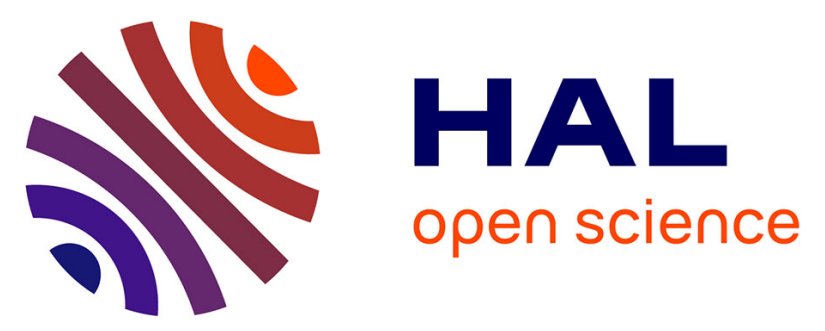

\title{
Isotretinoin and risk factors for suicide attempt: a population-based comprehensive case series and nested case-control study using 2010-2014 French Health Insurance Data
}

Catherine Droitcourt, Florence Poizeau, Sandrine Kerbrat, Frédéric Balusson, Erwan Drezen, André Happe, David Travers, Emmanuel Oger, Alain Dupuy

\section{To cite this version:}

Catherine Droitcourt, Florence Poizeau, Sandrine Kerbrat, Frédéric Balusson, Erwan Drezen, et al.. Isotretinoin and risk factors for suicide attempt: a population-based comprehensive case series and nested case-control study using 2010-2014 French Health Insurance Data. Journal of the European Academy of Dermatology and Venereology, 2020, 34 (6), pp.1293-1301. 10.1111/jdv.16005 . hal02363653

\section{HAL Id: hal-02363653}

\section{https://hal-univ-rennes1.archives-ouvertes.fr/hal-02363653}

Submitted on 9 Dec 2019

HAL is a multi-disciplinary open access archive for the deposit and dissemination of scientific research documents, whether they are published or not. The documents may come from teaching and research institutions in France or abroad, or from public or private research centers.
L'archive ouverte pluridisciplinaire HAL, est destinée au dépôt et à la diffusion de documents scientifiques de niveau recherche, publiés ou non, émanant des établissements d'enseignement et de recherche français ou étrangers, des laboratoires publics ou privés. 
DR. CATHERINE DROITCOURT (Orcid ID : 0000-0001-6714-6643)

Article type : Original Article

Isotretinoin and risk factors for suicide attempt: a population-based comprehensive case series and nested case-control study using 2010-2014 French Health Insurance Data

Catherine Droitcourt ${ }^{1,2,3,4}, \mathrm{MD}, \mathrm{PhD}$; Florence Poizeau ${ }^{1,3,4}, \mathrm{MD}$; Sandrine Kerbrat ${ }^{3,4_{\uparrow}}$, Frédéric Balusson $^{3}$, Erwan Drezen ${ }^{3}$, André Happe ${ }^{3,4}, \mathrm{PhD}$; David Travers ${ }^{5}$, MD; Emmanuel Oger ${ }^{3,4}$, MD, $\mathrm{PhD}$; Alain Dupuy ${ }^{1,3,4}, \mathrm{MD}, \mathrm{PhD}$

Affiliations: ${ }^{1}$ Department of Dermatology, CHU Rennes, F35000 Rennes, France; ${ }^{2}$ Univ Rennes, INSERM CIC 1414, F35000 Rennes, France; ${ }^{3}$ Univ Rennes, EA 7449 REPERES

"Pharmacoepidemiology and Health Services Research", F35000 Rennes, France; 4

Pharmacovigilance, Pharmacoepidemiology and Drug Information Departments, PEPS Research Consortium, F35000 Rennes, France; ${ }^{5}$ Department of Psychiatry, F35000 Rennes, France.

+Equal contribution

Key Words: acne, isotretinoin, suicide attempt

Words: 3187

Figures and Tables: 5

References: 42

Type of article: Original Article 
Address correspondence to: Dr Catherine Droitcourt, Department of Dermatology, Pontchaillou Hospital, 2 rue Henri le Guilloux 35000 Rennes, France, Tel: + 3329928 43 49, Fax: + 33299 2841 00, Mailto: catherine.droitcourt@chu-rennes.fr

Funding Source: This is an ancillary study from a research program funded by ANSM (Agence Nationale de Sécurité du Médicament, French Drug Regulatory Agency)

Conflict of interest: none to declare. 


\section{Abbreviations:}

AAD, American Academy of Dermatology

SA, Hospitalised Suicide Attempt

SNIIRAM, Système National d'Information Inter-régimes de l'Assurance Maladie

SNDS, Système National des Données de Santé

PMSI, Programme de Médicalisation des Systèmes d'information

ICD-10 code, International Classification of Diseases $10^{\text {th }}$ revision

CNIL, Commission Nationale de l'Informatique et des Libertés

OR, Odds Ratio

CI, Confidence Interval

IQR, Interquartile Range

SD, Standard Deviation 


\begin{abstract}
Background

Although the causal role of isotretinoin in suicidal behaviour is controversial, suicide attempts (SA) do occur among patients taking isotretinoin.
\end{abstract}

\title{
Objectives
}

To describe patient profiles and the management of isotretinoin among patients who committed or attempted suicide under treatment. To assess the risk factors for SA under isotretinoin.

\section{Methods}

We performed a comprehensive case series of suicides and SAs under isotretinoin, and a casecontrol study, using Nationwide French Health Insurance database.

The main analysis compared cases (subjects with a SA during a course of isotretinoin) to controls, individually matched for age, gender and rank of the current course; controls were to be exposed to isotretinoin at the index date (date of SA for the corresponding cases). The patients' psychiatric history at isotretinoin initiation was studied. In a secondary analysis, patients who continued their isotretinoin treatment after their SA were compared to patients who discontinued it.

\section{Results}

In all, 328018 subjects started a course of isotretinoin between January 1, 2010 and December 31, 2014 and 184 patients were hospitalised for a SA; half of them had a psychiatric history at initiation. In the multivariate analysis, psychiatric history and history of anxiety alone were risk factors for SA (OR, 18.21; CI95\%, 9.96-33.30 and 4.78; CI95\%, 2.44-9.33 respectively). Among 176 cases of SA with sufficient follow-up, 103 (58.5\%) carried on with their treatment after their SA. Treatment initiation by a dermatologist was inversely associated with the continuation of the treatment after a SA (OR, 0.38; CI95\%, 0.18-0.80).

\section{Conclusions}

SAs under isotretinoin are rare events and our results suggest that most of the patients concerned have a risk-prone profile detectable at the time of treatment initiation. The risk-benefit ratio of continuing isotretinoin after a SA warrants further careful evaluation. 


\section{Introduction}

Acne is a highly prevalent skin disorder, affecting $85 \%$ to $90 \%$ of adolescents and $12 \%$ of adults. ${ }^{1-}$

${ }^{7}$ Acne is moderate to severe for 15 to $20 \%$ of the adolescents affected. ${ }^{4}$ Patients with moderate to severe acne that is resistant to topical treatments and oral antibiotics, or patients with very severe acne (nodular acne) are treated with isotretinoin. ${ }^{8,9}$ The American Academy of Dermatology (AAD) also recommends prescribing isotretinoin to patients with acne that produces scarring or psychosocial distress. ${ }^{7}$ There are no other approved treatments for severe acne.

Concerning the safety of isotretinoin, two risks are closely monitored: a teratogenic risk, which is well established and a potential risk of psychiatric disorders. A possible link between isotretinoin and the occurrence of psychiatric disorders, in particular suicidal behaviours, is still under debate and cannot be fully excluded. ${ }^{10-14}$ Indeed, although the available data is conflicting and not sufficient to establish a causal association between isotretinoin and psychiatric disorders, warnings about this potential risk are given in the product information sheets and in agency regulations ${ }^{15-18}$ which have regularly issued recommendations for health professionals.

Furthermore, the issue of this potential risk is made more complex by the fact that subjects with moderate to severe acne are more likely to have suicidal ideations, ${ }^{19-22}$ depressive symptoms, ${ }^{19,23}$ altered self-image, ${ }^{22,24}$ attention disorders ${ }^{25}$ and fatigue ${ }^{26}$ than are subjects without acne or with mild acne. Psychiatric disorders linked to acne itself justify the need for appropriate health care provision $^{27}$ and the AAD recommends treating these patients with isotretinoin. ${ }^{7}$

No study on risk factors for suicidal behaviours has been conducted, however, because suicidal disorders under isotretinoin are rare events. The largest epidemiological study on suicidal behaviour and isotretinoin included only 14 suicide attempts and one suicide under treatment. ${ }^{13}$

From the French health insurance database, we collected information on patients who had attempted suicide or completed suicide under isotretinoin, over the 2010-2014 period, with the following objectives: 1 . Providing incidence data and patient characteristics, 2 . to analyse risk factors for suicide attempt (SA), and 3. to describe post-SA attitudes regarding isotretinoin treatment.

\section{Materials and Methods}




\section{Data sources}

SNIIRAM, now called SNDS, includes the French national medico-administrative reimbursement database for outpatient health care consumption and it is linked to the French hospital discharge database (PMSI: Programme de Médicalisation des Systèmes d'Information) through a single, anonymous civil registration system. ${ }^{28,29}$ This system covers almost the entire French population, corresponding to approximately 66 million people. The SNIIRAM-SNDS contains anonymous, individual data, including demographic data (gender, dates of birth and death, city of residence); long-term chronic disease status; reimbursements of outpatient health care consumption including drugs (name, date of dispensation and number of units and dosage dispensed per month), laboratory tests, consultations (date and number); and hospital data (public and private) including, diagnoses leading to hospitalization based on the ICD-10 code (International Classification of Diseases $10^{\text {th }}$ revision), date of admission and duration of hospital stay. This database contains all dispensations of oral isotretinoin in France.

Because the cause of death was not available within the SNIIRAM-SNDS database over this period, the French medical causes of death registry (CépiDC) was linked to the database on the basis of gender, birth month, year of birth, date of death, department and place of residence as the matching variables.

The study protocol was authorized by the National Institutional Review Board (Institut des Données de Santé) and by the Commission Nationale de l'Informatique et des Libertés (CNIL) (decision no. DE2015182, December 24, 2015) and was an ancillary study, part of a larger study assessing isotretinoin and suicide risk ${ }^{30}$.

\section{Population}

All subjects aged 10 to 50 years during the study period from January 1, 2010 to December 31, 2014, who had at least one dispensation of isotretinoin, were included.

\section{Isotretinoin exposure}

All isotretinoin dispensations at national level were recorded from January 1, 2010 to December 31, 2014. Isotretinoin was identified according the anatomical, therapeutic and chemical classification system (ATC) (World Health Organization), using the code D10BA01. A course of isotretinoin was defined by one or several dispensations with a time-lapse between two dispensations of 4 months or fewer. Patients were considered to be on the same course between the date of the first dispensation and the date of the last dispensation +1 month of isotretinoin within the course. If the time-lapse between two dispensations of isotretinoin was over four 
months, we considered that the patient had begun a new course of isotretinoin. Patients were considered to be exposed to isotretinoin during their treatment course and non-exposed otherwise. Suicide attempt (SA) and completed suicide

Suicide attempt was defined by a hospitalization for SA, identified from the diagnosis codes of the ICD-10 X60.x to X69.x, X70.x to X79.x and X80.x to X84.x. Completed suicide was identified from the diagnosis codes of the ICD-10 X60.x to X69.x, X70.x to X79.x, X80.x to X84.x, Y87.0, Y10.x to Y34.x, and R99 (eTable 1 in the Supplementary file). Only SAs and completed suicides occurring during isotretinoin exposure were considered.

\section{Covariables}

Among the potential risk factors for SA, we looked for factors linked to the patients' medical history, identified in the 12 months before the beginning of the isotretinoin treatment, and factors linked to isotretinoin treatment itself and its management:

- Potential individual psychiatric risk factors for SA identified within the 12 months before the start of the course of isotretinoin were the same variables of interest described in a previous study ${ }^{30}$ and have been summed up in three categories: psychiatric history, history of anxiety and no psychiatric history. The detailed description of these categories is given in the eText 1 in the Supplementary file.

- Potential risk factors linked to the course of isotretinoin itself and its medical management: the prescriber's speciality at the time of initiation (dermatologist or general practitioner), the daily dose before the date of SA (in milligrams), the cumulate dose between the start of the course and the date of the SA (in milligrams), and the brand name (CURACNE®, PROCUTA $\AA$, CONTRACNE®, ACNETRAIT $®)$. Since the number of cases and controls treated with PROCUTA ${ }^{\circ}$, CONTRACNE®, ACNETRAIT® was small, we created a categorical variable, CURACNE®/others.

- Others: area of residence (Ile de France, north-east, north-west, south-east, south-west France and Overseas Departments and territories)

\section{Study design and statistical analysis}

After providing a description of patients who attempted or committed suicide during isotretinoin exposure, we performed a matched nested case-control study to identify risk factors for SA during isotretinoin exposure. Completed suicides were not considered in this analysis: the knowledge that SAs and completed suicides in general have different risk factors ${ }^{31}$ precluded the grouping of the 
two; and the small number of suicides excluded the possibility of a separate case-control study devoted to suicides.

Cases

Cases were subjects with a SA during a course of isotretinoin. We excluded subjects with a course of isotretinoin starting in 2009 and continuing into 2010. SAs were identified through the ICD-10 hospitalization codes (see above) and the date of admission was used as the index date.

Controls

For each case, four controls were sought in the population exposed to isotretinoin: they were to be exposed to isotretinoin at the index date, to have started their course in the same calendar month, with no observed SA during that treatment course. Other matching variables included age (same year of birth $+/$ - one year), gender, and the rank of the current isotretinoin course (first vs second or more). This process did not preclude controls from having a history of SA before isotretinoin initiation. A control could be eligible to become a subsequent case, from the time of selection as a control (density sampling). ${ }^{32}$ It is worth noting that 2 cases could not be matched with controls and they were excluded. The number of controls per case were 4, 3, 2, 1 for 174, 2, 4 and 2 cases respectively.

\section{Case-control analysis}

The association between SA under isotretinoin and the different factors was estimated using odds ratios and their corresponding 95\% confidence interval, and univariate and multivariate conditional logistic regressions. Variables with $p \leq 0.3$ in the univariate analysis were included in the multivariate model. The model was further adjusted on age and area of residence. The LOGISTIC and PHREG procedures (with a STRATA option) were carried out on SAS/STAT enterprise guide 7.12 software v9.4 (SAS Institute, Inc., USA).

\section{Isotretinoin treatment after $S A$}

Among the cases (i.e. patients with SA during their isotretinoin course), some had their treatment discontinued while others continued to receive isotretinoin dispensations. We conducted a secondary analysis to assess the characteristics of patients who continued their course of isotretinoin after SA (post-SA users), and compared them with those who discontinued it after SA (discontinuers), using an unmatched logistic regression model. Cases with a follow-up period of fewer than four months after the last dispensation before the date of the SA were excluded from this analysis. 


\section{Results}

Descriptive characteristics of patients who attempted or committed suicide

A total of 328018 subjects between 10 and 50 years of age (183 869 males and 144149 females) had started a course of isotretinoin between January 1, 2010 and December 31, 2014 (Fig. 1). During the study period, 284558 subjects had one course of isotretinoin and 43460 more than one. Among them, 17 patients committed suicide and 184 were hospitalised for a SA, during their treatment. The incidence rate of SA under isotretinoin was 109.7 per 100000 person-years (CI95\%, 98.3-121.1), or one SA for 2107 courses of treatment. The incidence of suicide under isotretinoin was 10.1 per 100000 person-years (CI95\%, 6.6-13.6), or one suicide for 22802 patients starting a course of isotretinoin. The incidence rates of SA under isotretinoin are given in the Supplementary Figures 1 and 2, and Table 1.

The characteristics of patients with SA and who committed suicide are given in Table 1. For SAs, the mean (SD) age of patients was 23.2 (9.2) years, and 55.4\% (102) were females. The median exposure time before a SA was 83 days (IQR, 43-149) without any specific period (Fig. 2). The median cumulate dose before a SA was 1985 mg (IQR, 900-3899). Isotretinoin treatment was initiated by a dermatologist for 135 patients (73.4\%). At isotretinoin initiation, 66 patients (35.9\%) had a psychiatric history, 21 patients (11.4\%) had a history of anxiety, and 97 (52.7\%) had no psychiatric history. The median time-lapse between the last dispensation of isotretinoin and the date of hospitalization for SA was 17 days (IQR, 8-25).

For suicide, the mean (SD) age of patients was 30.6 (9.6) years, and 82.4\% (14) were males. The median exposure time before suicide was 78 days (IQR, 44-151). At isotretinoin initiation, the majority of patients had a psychiatric history (9 patients, $52.9 \%$ ).

\section{Risk factors for SA under isotretinoin}

The results of the matched case-control study comparing cases with SA to controls are presented in Table 2.

In the multivariate analysis, the major risk factor for SA under isotretinoin was a psychiatric history (OR, 18.21; CI95\%, 9.96-33.30). A history of anxiety was also a strong risk factor for SA under isotretinoin (OR, 4.78; CI95\%, 2.44-9.33). Conversely, the cumulate dose of isotretinoin was associated with a lower risk of SA (OR, 0.70; CI95\%, 0.58-0.87).

Continuation of the course of isotretinoin after a $S A$ :

Information on treatment course continuation or discontinuation was obtained for 176 cases: 103 $(58.5 \%)$ continued their course of isotretinoin after their SA with a median time-lapse of 21 days 
(IQR, 10-35) between hospitalization for SA and the next dispensation of isotretinoin after their SA, and $73(41.5 \%)$ discontinued their treatment. Among the patients who continued treatment, 8 of the 103 had a second SA during the course of isotretinoin.

In the comparison between continuers and discontinuers, initiation of isotretinoin by a dermatologist was associated with its discontinuation (OR, 0.38; CI95\%, 0.18-0.80). No other variables differed between continuers and discontinuers (Table 3).

Among the 59 patients who discontinued the treatment after the SA and had sufficient follow-up duration, $12(20.3 \%)$ started a subsequent course of isotretinoin within one year of the date of the SA (Fig. 1).

\section{Discussion}

In this nationwide, population-based, case-control study of the risk factors for SA among patients taking isotretinoin, we show that patients' psychiatric history and history of anxiety were strongly associated with SA under isotretinoin. Generally speaking, SA under isotretinoin is a rare event, concerning 1 out of 2107 isotretinoin courses and occurring at all stages in isotretinoin treatment. It is worth noting that isotretinoin treatment was continued after a SA for around $60 \%$ of patients. Our study is the largest to date, with a large number of SAs (184) and suicides (17) under isotretinoin, and it included a comparison among patients with acne treated with isotretinoin. In comparison, Sundstrom's study included 14 SAs and one suicide under treatment. ${ }^{13}$ We assessed the risk factors for SA under isotretinoin in a complex relationship between severe acne, psychiatric disorders, suicidal behaviour and isotretinoin. The issue of suicide risk is extremely difficult to approach on account of the possible confounding role of the presence of severe acne. ${ }^{13}$ Indeed, severe acne can itself induce suicidal disorders ${ }^{19-23,25}$ and treating acne efficiently with isotretinoin can improve the psychological burden of acne. ${ }^{27}$ In our study, we chose matched controls treated for at least the same duration as their cases up to the SA, and this design option should contribute to an adjustment on acne severity. Furthermore, isotretinoin is the only treatment for severe acne, antibiotics being generally given for less severe forms or before isotretinoin treatment. We also looked at the medical history available to prescribers at the time of initiation. Regarding isotretinoin treatment, we observed that SAs occurred at different moments throughout isotretinoin treatment. On the basis of the French and FDA pharmacovigilance data and the review of the literature of case reports, the time-lapse between isotretinoin initiation and suicidal behaviour was also variable from the start to the end of the treatment. ${ }^{33-36}$ Few case reports have 
suggested a potential daily dose-dependent effect of isotretinoin for psychiatric disorders, mainly depressive disorders ${ }^{33,37}$ or have suggested that suicidal ideation ${ }^{37}$ and higher doses of isotretinoin could be associated with more psychiatric symptoms. ${ }^{34}$ Our study did not support this hypothesis for suicidal behaviour. In a study based on medical-administrative databases in Quebec, the authors observed a trend towards a greater risk of depression with a higher cumulate dose, but with no statistical significance. ${ }^{12}$ In our study, the cumulate dose before a SA was associated with a lower risk of SA. With equal treatment durations between cases and controls, this finding was probably linked to an increase in isotretinoin dose that was faster for patients who were not susceptible to the outcome, enabling the cumulate dose to be obtained faster.

In France, until 2015, isotretinoin could be initiated either by a dermatologist or by a general practitioner. A treatment with isotretinoin initiated by a dermatologist was less associated with SA during treatment in univariate analysis. Furthermore, isotretinoin initiation by a dermatologist was strongly associated with treatment discontinuation after a SA under isotretinoin in multivariate analysis. Dermatologists are well-acquainted with isotretinoin management and well-informed of the potential risk of isotretinoin-induced suicidal behaviour. It could therefore be hypothesized that, firstly they carefully select the patients before initiating isotretinoin, and secondly, they observe a careful follow-up and specific psychiatric assessments in order to discontinue isotretinoin treatment if they observe any early psychiatric symptoms or deteriorating psychiatric conditions. In our previous study,

a lower risk of SA was observed among patients exposed to isotretinoin compared to the general population..$^{30}$ The decision whether or not to treat a patient with severe acne and psychiatric disorders remains a crucial issue. Decisions result from factors ranging from ignorance or failure to review the patients' medical history, to a well-informed decisional process taking into consideration the relative urgency to treat because of psychiatric disorders arising from severe acne, or again to reluctance to treat a patient with a psychiatric history. Thus the decision to continue treatment after a SA could be explained either by a lack of knowledge on this potential link, or by a choice justified on the grounds of treatment efficacy for severe acne and potential acne-related psychiatric disorders, or again by the knowledge of the absence of evidence for a risk shown in the main epidemiological studies.

The risks factors for SA under isotretinoin identified here are well-characterized risk factors for suicidal behaviour: psychiatric illnesses including major depression, bipolar, psychotic and personality disorders ${ }^{31,38,39}$ and history of SA. ${ }^{40}$ Among the 85 reports received by the FDA on 
hospitalizations for depression, suicidal ideation or SA over an 18-year period under isotretinoin, $48(44 \%)$ had a psychiatric history and $57(52 \%)$ had other contributing factors. ${ }^{33}$ The share of risk linked to isotretinoin itself in a context of psychiatric history is difficult to capture. The population with psychiatric history could probably commit SA outside isotretinoin exposure. It is even possible that leaving a severe acne (suspected to be a risk factor for SA) ${ }^{19,22}$, untreated would increase the overall number of SAs. Furthermore, Sundstrom et al. showed that patients with a history of SA before isotretinoin treatment had no additional risk for SA during treatment, suggesting that these patients would be eligible for isotretinoin treatment. ${ }^{13}$. The balance to be found is that between leaving severe acne untreated among people with a psychiatric history and giving an effective treatment with increased surveillance for these patients.

\section{Strengths and limitations}

Our study has several strengths. First, the study was based on exhaustive data recording isotretinoin dispensations across approximately $98 \%$ of the French population, with no attrition bias. Second, this study investigated a recent period in which a risk management plan was implemented among prescribers in different European countries and in the United States. Certain limitations should however be discussed. First, our data was based on isotretinoin reimbursements; we cannot be sure that data on actual consumption would be perfectly similar. However, reimbursement data has been found to be highly correlated with drug consumption for regularly used medications. ${ }^{41}$ Second, we only had data on hospitalised SAs; they included SAs processed in emergency departments with a stay of at least eight hours in these departments; nonhospitalised SAs were not included here. In one study, about $80 \%$ of general practitioners in primary care settings reported referring patients who had attempted suicide to hospital, mainly to the emergency departments. ${ }^{42}$ Third, neither clinical data, in particular the clinical course of severe acne, nor social factors were available on the SNIIRAM-SNDS database. Fourth, we grouped psychiatric disorders in category of psychiatric history without individualizing depression. Since depressive disorders are a major risk factor for SA, they are very often associated with other psychiatric disorders. $^{31}$

No definitive conclusion for practice can be drawn from our observational data because the type and magnitude of indication biases cannot be estimated. Among patients having risk factors for SA, the role of severe acne as an additional risk factor in itself should be carefully assessed, on an individual basis. In this context, not prescribing an efficacious anti-acne treatment could be harmful. For the same reason, i.e. limitation due to indication biases, our data does not enable us 
to provide general rules for continuing or discontinuing isotretinoin after a SA, and thorough discussion should take place, on an individual basis. 


\section{Acknowledgements}

\section{Author contributions:}

Dr Droitcourt had full access to all of the data in the study and take responsibility for the integrity of the data and the accuracy of the data analysis.

Study concept and design: Dr Droitcourt, Dr Poizeau, Miss Kerbrat, Pr Oger and Pr Dupuy.

Acquisition of data: Dr Droitcourt, Dr Poizeau and Miss Kerbrat.

Analysis and interpretation of data: Dr Droitcourt, Dr Poizeau, Miss Kerbrat, Mr Balusson, Pr

Oger and Pr Dupuy.

Statistical analysis: Dr Droitcourt, Dr Poizeau and Miss Kerbrat.

Drafting of the manuscript: Dr Droitcourt and Pr Dupuy.

Critical revision of the manuscript for important intellectual content: Dr Droitcourt, Dr Poizeau, Miss Kerbrat, Mr Balusson, Mr Drezen, Mr Happe, Dr Travers, Pr Oger and Pr Dupuy.

Study supervision: Pr Dupuy and Pr Oger.

Conflict of interest disclosures: none to declare.

Funding/Support: This is an ancillary study from a research program funded by ANSM (Agence Nationale de Sécurité du Médicament, French Drug Regulatory Agency) 


\section{References}

1. Goulden V, Stables GI, Cunliffe WJ. Prevalence of facial acne in adults. $J$ Am Acad Dermatol 1999; 41:577-80.

2. Daniel F, Dreno B, Poli F, Daniel F, Dreno B, Poli F, Auffret N, Beylot C, Bodokh I, et al. Descriptive epidemiological study of acne on scholar pupils in France during autumn 1996. Ann Dermatol Venereol 2000; 127:273-8.

3. Yahya H. Acne vulgaris in Nigerian adolescents-prevalence, severity, beliefs, perceptions, and practices. Int J Dermatol 2009; 48:498-505.

4. Ghodsi SZ, Orawa H, Zouboulis CC. Prevalence, severity, and severity risk factors of acne in high school pupils: a community-based study. J Invest Dermatol 2009; 129:2136-41.

5. Williams HC, Dellavalle RP, Garner S. Acne vulgaris. Lancet 2012; 379:361-72.

6. Bhate K, Williams HC. Epidemiology of acne vulgaris. Br J Dermatol 2013; 168:474-85.

7. Roman CJ, Cifu AS, Stein SL. Management of Acne Vulgaris. JAMA 2016; 316:14021403.

8. http://www.sfdermato.com/media/pdf/recommandation/label-recommandations-acne-postcollege-54ac60356d1b9584a71ccaac92cf3724.pdf. (last accessed June 26, 2019).

9. Le Cleach L, Lebrun-Vignes B, Bachelot A, Beer F, Berger P, Brugère S, et al; French Acne Guidelines Working Group and Centre of Evidence of Dermatology. Guidelines for the management of acne: recommendations from a French multidisciplinary group. $\mathrm{Br} J$ Dermatol 2017; 177:908-913.

10. Jick SS, Kremers HM, Vasilakis-Scaramozza C. Isotretinoin use and risk of depression, psychotic symptoms, suicide, and attempted suicide. Arch Dermatol 2000; 136:1231-6.

11. Hersom K, Neary MP, Levaux HP, Klaskala W, Strauss JS. Isotretinoin and antidepressant pharmacotherapy: a prescription sequence symmetry analysis. J Am Acad Dermatol 2003; 49:424-32.

12. Azoulay L, Blais L, Koren G, LeLorier J, Bérard A. Isotretinoin and the risk of depression in patients with acne vulgaris: a case-crossover study. J Clin Psychiatry 2008; 69:526-32.

13. Sundström A, Alfredsson L, Sjölin-Forsberg G, Gerdén B, Bergman U, Jokinen J. Association of suicide attempts with acne and treatment with isotretinoin: retrospective Swedish cohort study. BMJ 2010; 341:c5812. 
14. Langan SM, Batchelor JM. Acne, isotretinoin and suicide attempts: a critical appraisal. $\mathrm{Br}$ J Dermatol 2011;164:1183-5; discussion 1185-6.

15. U.S. Food and Drug Administration (FDA), Medication guide, revised in January 2010. https://www.accessdata.fda.gov/drugsatfda_docs/label/2010/018662s061MedGuide.pdf. (last accessed September 5, 2019).

16. Agence Nationale de Sécurité des Médicaments et des produits de santé (ANSM). Medication guide of risk minimization measures, September, 2015. http://ansm.sante.fr/var/ansm_site/storage/original/application/60aa4def169fb548f5c2f545 41857aae.pdf. (last accessed September 5, 2019).

17. GOV.UK. Guidance, isotretinoin for severe acne: uses and effects, December 18, 2014. https://www.gov.uk/government/publications/isotretinoin-for-severe-acne-uses-andeffects/isotretinoin-for-severe-acne-uses-and-effects\#further-information. (last accessed September 5, 2019).

18. GOV.UK. Public assessment review, November 2014. https://www.gov.uk/government/uploads/system/uploads/attachment_data/file/391670/isot retinoin_and_psychiatric_disorders_PAR_Final_web.pdf. (last accessed September 5, 2019).

19. Gupta MA, Gupta AK. Depression and suicidal ideation in dermatology patients with acne, alopecia areata, atopic dermatitis and psoriasis. Br J Dermatol 1998; 139:846-50.

20. Picardi A, Mazzotti E, Pasquini P. Prevalence and correlates of suicidal ideation among patients with skin disease. $J$ Am Acad Dermatol 2006; 54:420-6.

21. Rehn LM, Meririnne E, Höök-Nikanne J, Isometsä E, Henriksson M. Depressive symptoms and suicidal ideation during isotretinoin treatment: a 12-week follow-up study of male Finnish military conscripts. J Eur Acad Dermatol Venereol 2009; 23:1294-7.

22. Halvorsen JA, Stern RS, Dalgard F, Thoresen M, Bjertness E, Lien L. Suicidal ideation, mental health problems, and social impairment are increased in adolescents with acne: a population-based study. J Invest Dermatol 2011; 131:363-370.

23. Purvis D, Robinson E, Merry S, Watson P. Acne, anxiety, depression and suicide in teenagers; A cross- sectional survey of New Zealand secondary school students. J Pediatr Child Health 2006; 42:793- 796. 
24. Dalgard F, Gieler U, Holm JØ, Bjertness E, Hauser S. Self-esteem and body satisfaction among late adolescents with acne: results from a population survey. $J$ Am Acad Dermatol 2008; 59:746-51.

25. Gupta MA, Gupta AK, Vujcic B. Increased frequency of Attention Deficit Hyperactivity Disorder (ADHD) in acne versus dermatologic controls: analysis of an epidemiologic database from the US. J Dermatolog Treat 2014; 25:115-8.

26. Misery L, Wolkenstein P, Amici JM, Maghia R, Brenaut E, Cazeau C, et al. Consequences of acne on stress, fatigue, sleep disorders and sexual activity: a population-based study. Acta Derm Venereol 2015; 95:485-8.

27. Misery L. Consequences of psychological distress in adolescents with acne. J Invest Dermatol 2011; 131:290-2.

28. Palmaro A, Moulis G, Despas F, Dupouy J, Lapeyre-Mestre M. Overview of drug data within French health insurance databases and implications for pharmacoepidemiological studies. Fundam Clin Pharmacol 2016; 30:616-624.

29. Tuppin P, Rudant J, Constantinou P, Gastaldi-Ménager C, Rachas A, de Roquefeuil L, et al. Value of a national administrative database to guide public decisions: From the système national d'information interrégimes de l'Assurance Maladie (SNIIRAM) to the système national des données de santé (SNDS) in France. Rev Epidemiol Sante Publique 2017; 65 (Suppl. 4):S149-S167.

30. Droitcourt C, Nowak E, Rault C, Happe A, Le Nautout B, Kerbrat S, et al. Risk of suicide attempt associated with isotretinoin: nationwide cohort and nested case-time-control study. Int J Epidemiology 2019

31. Turecki G, Brent DA. Suicide and suicidal behaviour. Lancet 2016; 387:1227-39.

32. Rothman KJ, Greenland S, Lash TL, eds Design strategies to improve study accuracy.Modern epidemiology.3rd ed. Lippincott Williams \& Wilkins, 2008.

33. Wysowski DK, Pitts M, Beitz J. An analysis of reports of depression and suicide in patients treated with isotretinoin. J Am Acad Dermatol 2001; 45:515-9.

34. Bremner JD, Shearer KD, McCaffery PJ. Retinoic acid and affective disorders: the evidence for an association. Clin Psychiatry 2012; 73:37-50.

35. Le Moigne M, Bulteau S, Grall-Bronnec M, Gerardin M, Fournier JP, Jonville-Bera AP, et al. Psychiatric disorders, acne and systemic retinoids: comparison of risks. Expert Opin Drug Saf 2017; 16:989-995. 
36. Le Moigne M, Fournier JP, Bulteau S, Grall-Bronnec M, Khammari A, Victorri-Vigneau $\mathrm{C}$, et al. Psychiatric disorders with systemic retinoids: a systematic review of case reports. Br J Dermatol 2018; 178:278-280.

37. $\mathrm{Ng} \mathrm{CH}$, Tam MM, Hook SJ. Acne, isotretinoin treatment and acute depression. World $J$ Biol Psychiatry 2001; 2:159-61.

38. Hoertel N, Franco S, Wall MM, Oquendo MA, Kerridge BT, Limosin F, et al. Mental disorders and risk of suicide attempt: a national prospective study. Mol Psychiatry 2015; 20:718-26.

39. Holma KM, Haukka J, Suominen K, Valtonen HM, Mantere O, Melartin TK, et al. Differences in incidence of suicide attempts between bipolar I and II disorders and major depressive disorder. Bipolar Disord 2014; 16:652-61.

40. Carroll R, Metcalfe C, Gunnell D. Hospital presenting self-harm and risk of fatal and nonfatal repetition: systematic review and meta-analysis. PLoS One 2014; 9:e89944.

41. Noize P, Bazin F, Pariente A, Dufouil C, Ancelin ML, Helmer C, et al. Validity of chronic drug exposure presumed from repeated patient interviews varied according to drug class. $J$ Clin Epidemiol 2012; 65:1061-8.

42. Le Pont F, Letrilliart L, Massari V, Dorléans Y, Thomas G, Flahault A. Suicide and attempted suicide in France: results of a general practice sentinel network, 1999-2001. Br J Gen Pract 2004; 54:282-4. 


\section{Tables}

Table 1: Characteristics of patients with suicide attempt (SA) and completed suicide under isotretinoin, and characteristics of courses of isotretinoin

Table 2: Univariate and multivariate analysis of factors associated with hospitalised suicide attempt (SA) under a course of oral isotretinoin

Table 3: Univariate analysis of characteristics of isotretinoin discontinuers compared to isotretinoin continuers 


\section{Legends and Figures}

Figure 1: Flow-chart

\section{Legends}

Abbreviations: SA, Suicide Attempt

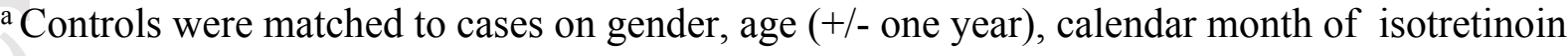
initiation, rank of course of isotretinoin

${ }^{\mathrm{b}}$ Insufficient follow-up $=$ fewer than four months after the last dispensation before the date of SA

${ }^{\mathrm{c}}$ Insufficient follow-up $=$ at least twelve months after the date of SA

Figure 2: Time lapse between the start of the course of oral isotretinoin and the suicide attempt.

\section{Legends}

Horizontal bar chart: each bar represents a patient.

The length of the bar indicates the duration of the course of isotretinoin until the date of suicide attempt. 
Table 1: Characteristics of patients with suicide attempt (SA) or completed suicide under isotretinoin and characteristics of courses of isotretinoin

\begin{tabular}{|c|c|c|}
\hline & $\begin{array}{c}\text { Patients with } \\
\text { suicide attempt } \\
\quad(n=184)\end{array}$ & $\begin{array}{c}\text { Patients with } \\
\text { completed suicide } \\
\quad(\mathbf{n}=17)\end{array}$ \\
\hline \multicolumn{3}{|l|}{ Age } \\
\hline Mean (SD) & $23.2(9.2)$ & $30.6(9.6)$ \\
\hline Median (IQR) & $20(16 ; 27)$ & $30(23 ; 37)$ \\
\hline \multicolumn{3}{|l|}{ Gender } \\
\hline Male, n (\%) & 82 (44.6) & $14(82.4)$ \\
\hline Female, n (\%) & $102(55.4)$ & $3(17.6)$ \\
\hline \multicolumn{3}{|l|}{ Psychiatric history } \\
\hline None $(R e f), \mathrm{n}(\%)$ & $97(52.7)$ & $6(35.3)$ \\
\hline Anxiety ${ }^{*}, \mathrm{n}(\%)$ & $21(11.4)$ & $2(11.8)$ \\
\hline Psychiatric history $^{\dagger}, \mathrm{n}(\%)$ & $66(35.9)$ & $9(52.9)$ \\
\hline Long-term psychiatric illness, $\mathrm{n}(\%)$ & $16(8.7)$ & $4(23.5)$ \\
\hline $\begin{array}{l}\text { Hospitalisation in medical or surgical unit } \\
\text { for psychiatric disorder, } \mathrm{n}(\%)\end{array}$ & $21(11.4)$ & $1(5.9)$ \\
\hline Hospitalisation in psychiatry unit, $\mathrm{n}(\%)$ & $10(5.4)$ & $1(5.9)$ \\
\hline Psychotropic treatment, $\mathrm{n}(\%)$ & $53(28.8)$ & $6(35.3)$ \\
\hline Hospitalisation for suicide attempt, $\mathrm{n}(\%)$ & $19(10.3)$ & $0(0)$ \\
\hline \multicolumn{3}{|l|}{ Rank of the course } \\
\hline First, n (\%) & $145(78.8)$ & $12(70.6)$ \\
\hline Second or more, $\mathrm{n}(\%)$ & $39(21.2)$ & $5(29.4)$ \\
\hline \multicolumn{3}{|l|}{$\begin{array}{l}\text { Isotretinoin exposure time before } \mathrm{SA} \text {, in } \\
\text { days }\end{array}$} \\
\hline Mean (SD) & $114(109)$ & $153(242)$ \\
\hline Median (IQR) & $83(43 ; 149)$ & $78(44 ; 151)$ \\
\hline \multicolumn{3}{|l|}{$\begin{array}{l}\text { Cumulate dose of isotretinoin before SA or } \\
\text { suicide, in mgs }\end{array}$} \\
\hline Mean (SD) & $2647(2245)$ & $3429(4133)$ \\
\hline Median (IQR) & $1985(900 ; 3895)$ & $1860(800 ; 4750)$ \\
\hline \multicolumn{3}{|l|}{$\begin{array}{l}\text { Prescribed daily dose of isotretinoin in the } \\
\text { month preceding SA, in mgs }\end{array}$} \\
\hline Mean (SD) & $29(13)$ & $29(11)$ \\
\hline Median (IQR) & $30(20 ; 40)$ & $30(20 ; 40)$ \\
\hline \multicolumn{3}{|l|}{ Mode of suicide attempt $\mathrm{t}^{\S}$} \\
\hline Intentional self-poisoning (medications), $\mathrm{n}(\%)$ & $141(77.5)$ & $2(11.8)$ \\
\hline $\begin{array}{l}\text { Intentional self-poisoning (alcohol, solvents, } \\
\text { gases, pesticides, chemicals), n (\%) }\end{array}$ & $13(7.1)$ & $1(5.9)$ \\
\hline $\begin{array}{l}\text { Intentional self-harm by hanging, } \\
\text { strangulation, suffocation, } \mathrm{n}(\%)\end{array}$ & $2(1.1)$ & $4(23.5)$ \\
\hline $\begin{array}{l}\text { Intentional self-harm by handgun discharge, } \mathrm{n} \\
(\%)\end{array}$ & $0(0)$ & $2(11.8)$ \\
\hline $\begin{array}{l}\text { Intentional self-harm by other and unspecified } \\
\text { firearm discharge, } \mathrm{n}(\%)\end{array}$ & $0(0)$ & $1(5.9)$ \\
\hline
\end{tabular}




\begin{tabular}{|l|c|c|}
\hline $\begin{array}{l}\text { Intentional self-harm by sharp or blunt object, } \\
\mathrm{n}(\%)\end{array}$ & $18(9.9)$ & $1(5.9)$ \\
\hline $\begin{array}{l}\text { Intentional self-harm by jumping from a high } \\
\text { place, } \mathrm{n}(\%)\end{array}$ & $1(0.5)$ & $1(5.9)$ \\
\hline Others, $\mathrm{n}(\%)$ & $20(11)$ & $5(29.4)$ \\
\hline Incidence rate (per 100 000 person-years), \\
per calendar year
\end{tabular}

Abbreviations: N, number of patients with suicide attempt under isotretinoin; SA, suicide attempt; SD, standard deviation; IQR, interquartile range; mgs, milligrams

* Anxiolytic treatment alone identified using the ATC codes: N05BA, N05BB and N05BX

${ }^{\dagger}$ History of hospitalized suicide attempt in the 12 months before the start of the course of isotretinoin identified using the ICD-10 diagnostic codes X60.X to X69.x, X70.X to X79.X and X80.x to X84.X (codes defined in Table SX in the supplementary material),

and/or history of psychiatric illness defined by long-term psychiatric illness status (long-term chronic disease giving entitlement to $100 \%$ health insurance coverage) and/or hospitalization in medical or surgical unit for psychiatric disorder identified using the ICD-10 diagnostic codes F05.x to F09.x, F10.x to F19.x, F20 to F29, F30 to F39, F40 to F48, F50 to F59, F60 to F69, F80 to F89, F90 to F98 and F99 (codes defined in eTable 2 in the supplementary material) and/or hospitalization in a psychiatric unit and/or psychotropic treatment, identified using the anatomical, therapeutic and chemical classification (ATC) codes: ATC: NO5AX, N06XX, N07BB and N07CC

$\S^{\S}$ Total percentage can be greater than 100 because cases could have two or more mode of suicide attempt for the same hospitalization 
Table 2: Univariate and multivariate analyses of factors associated with hospitalized suicide attempt (SA) under a course of oral isotretinoin

\begin{tabular}{|c|c|c|c|c|}
\hline & $\begin{array}{c}\text { Cases } \\
(\mathrm{n}=182)\end{array}$ & $\begin{array}{l}\text { Controls }^{*} \\
(\mathrm{n}=712)\end{array}$ & $\begin{array}{c}\text { Univariate } \\
\text { Crude Odds ratio } \\
\text { (CI 95\%) }\end{array}$ & $\begin{array}{c}\text { Multivariate } \\
\text { Adjusted }^{\text {II }} \text { Odds ratio } \\
\text { (CI 95\%) }\end{array}$ \\
\hline $\begin{array}{l}\text { Type of prescriber at the } \\
\text { initiation of oral isotretinoin } \\
\text { course } \\
\text { General Practitioner (Ref), n (\%) } \\
\text { Dermatologist, n (\%) }\end{array}$ & $\begin{array}{c}47(25.8) \\
135(74.2)\end{array}$ & $\begin{array}{l}129(18.1) \\
583(81.9)\end{array}$ & $\begin{array}{c}1 \\
0.66(0.45-0.96)\end{array}$ & $0.92(0.58-1.46)$ \\
\hline $\begin{array}{l}\text { Isotretinoin brand name } \\
\text { CURACNE® (Ref), n (\%) } \\
\text { Others, n (\%) }\end{array}$ & $\begin{array}{l}112(61.5) \\
70(38.5)\end{array}$ & $\begin{array}{l}433(60.8) \\
279(39.2)\end{array}$ & $\begin{array}{c}1 \\
1.03(0.73-1.44)\end{array}$ & \\
\hline $\begin{array}{l}\text { Cumulate dose of isotretinoin } \\
\text { before index date, in mgs (in } \\
\text { increments of } 1000 \text { mgs) } \\
\text { Mean (SD) }\end{array}$ & $2581(2147)$ & $2956(2377)$ & $0.77(0.68-0.89)$ & $0.77(0.68-0.89)$ \\
\hline $\begin{array}{l}\text { Daily dose of isotretinoin } \\
\text { before index date, in mgs (in } \\
\text { increments of } 20 \text { mgs) } \\
\text { Mean (SD) }\end{array}$ & $29.9(13.5)$ & $32.2(12.8)$ & $0.75(0.56-0.98)$ & $1.05(0.69-1.60)$ \\
\hline Psychiatric history & & & & \\
\hline $\begin{array}{l}\text { No (Ref), n (\%) } \\
\text { Psychiatric history }{ }^{\dagger,} \text { n (\%) } \\
\text { Anxiety }{ }^{\ddagger}, \mathrm{n}(\%)\end{array}$ & $\begin{array}{l}97(53.3) \\
64(35.1) \\
21(11.5)\end{array}$ & $\begin{array}{c}631(88.6) \\
42(5.9) \\
39(5.5)\end{array}$ & $\begin{array}{c}1 \\
13.84(8.01-23.91) \\
4.60(2.45-8.63)\end{array}$ & $\begin{array}{c}18.21(9.96-33.30) \\
4.78(2.44-9.33)\end{array}$ \\
\hline
\end{tabular}

Abbreviations: $\mathrm{N}$, number of patients; mgs, milligrams; CI, confidence interval

"Matching variables: age (same year of birth $+/$ - one year), gender, calendar month of the initiation of a course of oral isotretinoin and number of courses of oral isotretinoin (one vs several courses).

${ }^{\dagger}$ History of hospitalised suicide attempt in the 12 months before the start of the course of isotretinoin identified using the ICD-10 diagnostic codes X60.x to X69.x, X70.x to X79.x and X80.x to X84.x (codes defined in eTable 1 in the supplementary material),

and/or history of psychiatric illness defined by long-term psychiatric illness status (long-term chronic disease giving entitlement to $100 \%$ health insurance coverage) and/or hospitalisation in medical or surgical unit for a psychiatric disorder identified using the ICD-10 diagnostic codes F05.x to F09.x, F10.x to F19.x, F20 to F29, F30 to F39, F40 to F48, F50 to F59, F60 to F69, F80 to F89, F90 to F98 and F99 (codes defined in eTable 2 in the supplementary material) and/or hospitalisation in a psychiatric unit and/or psychotropic treatment, identified using the anatomical, therapeutic and chemical classification (ATC) codes: ATC: NO5 AX, N06XX, N07BB and N07CC ${ }^{\ddagger}$ Only anxiolytic treatment identified using the ATC codes: N05BA, N05BB and N05BX

"I adjusted on age and area of residence 
Table 3: Univariate analysis of the characteristics of isotretinoin discontinuers compared to isotretinoin continuers

\begin{tabular}{|c|c|c|c|c|}
\hline & $\begin{array}{c}\text { Discontinuers } \\
(n=73)\end{array}$ & $\begin{array}{c}\text { Continuers } \\
(n=103)\end{array}$ & $\begin{array}{c}\text { Odds ratio } \\
\text { (CI 95\%) }\end{array}$ & P-value \\
\hline \multicolumn{5}{|l|}{ Gender } \\
\hline Females (Ref), n (\%) & $43(58.9 \%)$ & $53(51.5 \%)$ & 1 & \\
\hline Males, n (\%) & $30(41.1 \%)$ & $50(48.5 \%)$ & $1.35(0.73-2.47)$ & 0.33 \\
\hline \multicolumn{5}{|l|}{ Age, in years } \\
\hline Mean (SD) & $22.1(8.7)$ & $23.9(9.6)$ & $1.02(0.98-1.06)$ & 0.19 \\
\hline \multicolumn{5}{|l|}{$\begin{array}{l}\text { Age at the initiation of the } \\
\text { course of oral isotretinoin } \\
\text { (years) }\end{array}$} \\
\hline 10 to 20 years (Ref), $\mathrm{n}(\%)$ & $39(53.4 \%)$ & $46(44.7 \%)$ & 1 & \\
\hline 20 to 25 years, $\mathrm{n}(\%)$ & $11(15.1 \%)$ & $20(19.4 \%)$ & $1.54(0.66-3.60)$ & \\
\hline 26 to 50 years, $\mathrm{n}(\%)$ & $23(31.5 \%)$ & $37(35.9 \%)$ & $1.36(0.70-2.67)$ & 0.5 \\
\hline \multicolumn{5}{|l|}{$\begin{array}{l}\text { Type of prescriber at the } \\
\text { initiation of the course of oral } \\
\text { isotretinoin }\end{array}$} \\
\hline General Practitioner (Ref), $\mathrm{n}(\%)$ & $12(16.4 \%)$ & $35(34 \%)$ & 1 & \\
\hline Dermatologist, n (\%) & $61(83.6 \%)$ & $68(66.0 \%)$ & $0.38(0.18-0.80)$ & 0.01 \\
\hline \multicolumn{5}{|l|}{$\begin{array}{l}\text { Isotretinoin exposure time } \\
\text { before } S A \text {, in davs }\end{array}$} \\
\hline Mean (SD) & $101(76)$ & $117(109)$ & $1.05(0.95-1.16)$ & 0.29 \\
\hline \multicolumn{5}{|l|}{ Number of medical } \\
\hline Mean (SD) & $2.4(3.4)$ & $1.8(2.0)$ & $0.91(0.81-1.03)$ & 0.14 \\
\hline \multicolumn{5}{|l|}{ Cumulate dose of isotretinoin } \\
\hline Mean (SD) & $2538(2122)$ & $2657(2187)$ & $1.03(0.89-1.18)$ & 0.71 \\
\hline $\begin{array}{l}\text { Daily dose of isotretinoin before } \\
\text { index date, in } \mathbf{m g s} \text { (in } \\
\text { increments of } 20 \mathrm{mgs} \text { ) }\end{array}$ & & & & \\
\hline Mean (SD) & $28.4(9.9)$ & $30.6(15.6)$ & $1.28(0.80-2.06)$ & 0.31 \\
\hline \multicolumn{5}{|l|}{ Isotretinoin brand name } \\
\hline CURACNE® (Ref), n (\%) & $42(57.6 \%)$ & $68(66.0 \%)$ & 1 & \\
\hline Others, n (\%) & $31(42.4 \%)$ & $35(34.0 \%)$ & $1.23(0.68-2.33)$ & 0.45 \\
\hline \multicolumn{5}{|l|}{ Psychiatric history } \\
\hline None (Ref), n (\%) & $44(60.3 \%)$ & $50(48.5 \%)$ & 1 & \\
\hline Psychiatric history ${ }^{*}, \mathrm{n}(\%)$ & $21(28.3 \%)$ & $40(38.8 \%)$ & $1.68(0.86-3.26)$ & \\
\hline Anxiety $^{\dagger}, \mathrm{n}(\%)$ & $8(11.0 \%)$ & $13(12.6 \%)$ & $1.43(0.54-3.77)$ & 0.3 \\
\hline
\end{tabular}

Abbreviations: N, number of patients; SA, suicide attempt; mgs, milligrams; SD, standard deviation; CI, confidence interval

${ }^{*}$ History of hospitalized suicide attempt in the 12 months before the start of the course of isotretinoin identified using the ICD-10 diagnostic codes X60.x to X69.x, X70.x to X79.X and X80.x to X84.X (codes defined in eTable 1 in the supplementary material),

and/or history of psychiatric illness defined by long-term psychiatric illness status (long-term chronic disease giving entitlement to $100 \%$ health insurance coverage) and/or hospitalization in medical or surgical unit for psychiatric disorder identified using the ICD-10 diagnostic codes F05.x to F09.x, F10.x to F19.x, F20 to F29, F30 to F39, F40 to F48, F50 to F59, F60 to F69, F80 to F89, F90 to F98 and F99 (codes 
defined in eTable 2 in the supplementary material) and/or hospitalization in a psychiatric unit and/or psychotropic treatment, identified using the anatomical, therapeutic and chemical classification (ATC) codes: ATC: NO5 AX, N06XX, N07BB and N07CC

${ }^{\dagger}$ Only anxiolytic treatment identified using the ATC codes: N05BA, N05BB and N05BX 
Figure 1: Flow-chart

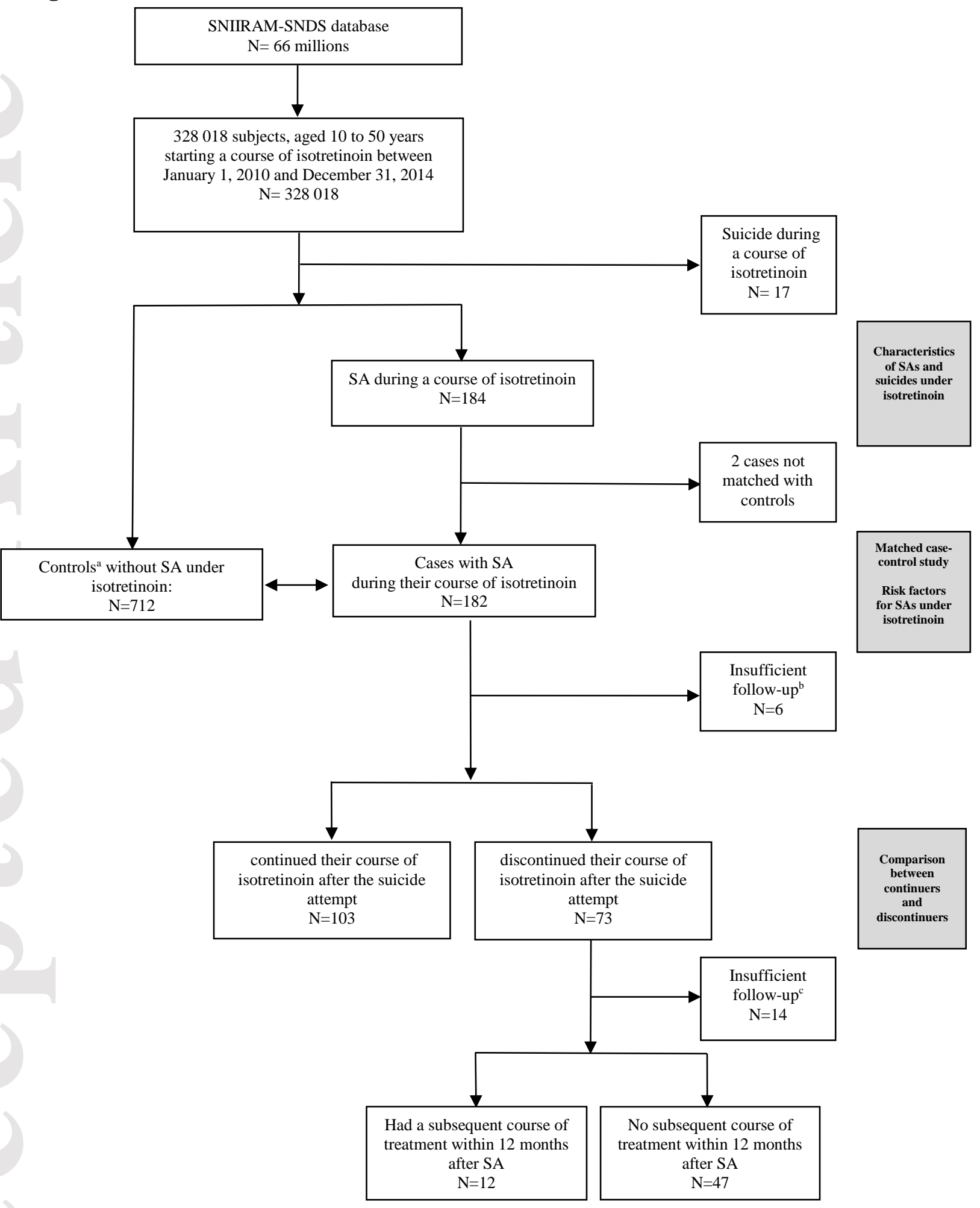

Abbreviations: SA, Suicide Attempt

${ }^{\text {a }}$ Controls were matched to cases on gender, age (+/- one year), calendar month of isotretinoin initiation, rank of course of isotretinoin

${ }^{\mathrm{b}}$ Insufficient follow-up = fewer than four months after the last dispensation before the date of SA

${ }^{\mathrm{c}}$ Insufficient follow-up $=$ at least twelve months after the date of SA 
Figure 2: Time lapse between the start of the course of oral isotretinoin and the suicide attempt.

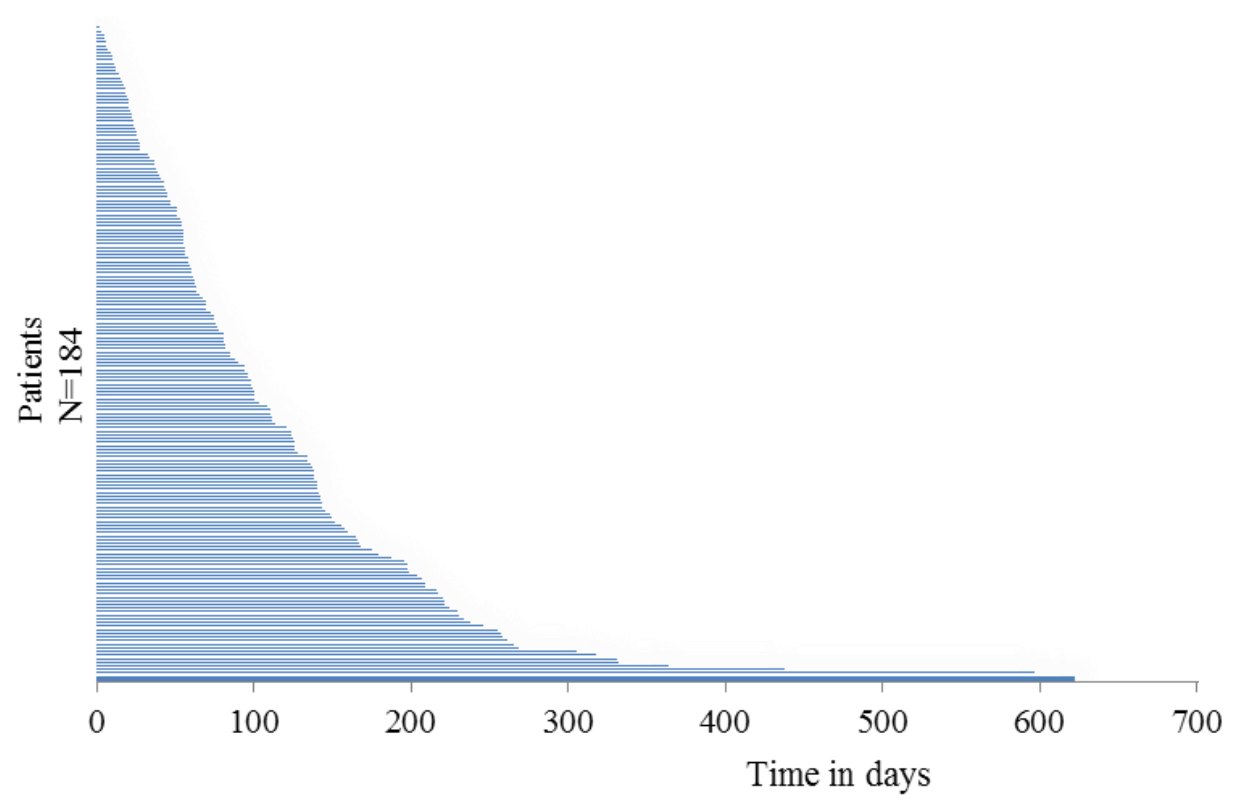

Horizontal bar chart: each bar represents a patient.

The length of the bar indicates the duration of the course of isotretinoin until the date of suicide attempt. 